\title{
ANATOMIA DO XILEMA SECUNDÁRIO DE Mimosa berroi Burk.
}

\author{
José Newton Cardoso Marchiori \\ Departamento de Ciências Florestais - Centro de Ciências Rurais \\ UFSM - Santa Maria, RS
}

\section{RESUMO}

São descritos os caracteres anatômicos da madeira de Mimosa ben Burk. e fornecidos 29 dados quantitativos de sua estrutura xilemática. A descriçi é ilustrada com fotromicrografias, tomadas nos três planos anatômicos. A estrutu da madeira é comparada com referências da literatura para espécies afins, e análise taxonômico-filogenética.

PALAVRAS-CHAVE: Anatomia da madeira, Leguminosae, Mimosoideae, Mimo berroi, Lepidotae

\section{SUMMARY}

MARCHIORI, J.N.C., 1996. Anatomy nof the wood of Mimosa berroi Burk.

The wood anatomy or Mimosa berroi Burk is described, based on : quantitative features of its xylem structure. The description is illustrated $w$ photomicrographs, taken from the three anatomical sections. The anatomic structure is compared with literature references to allied species, in a taxonom and phylogenetic analysis.

KEYWORDS : Wood Anatomy, Leguminosae, Mimosoideae, Mimosa berr Lepidotae. 


\section{INTRODUÇÃO}

O gênero Mimosa L. é um dos mais conhecidos das leguminosas, por estar associado ao nome de um dos três sub-grupos desta família botânica. $\mathrm{Na}$ época de Linnaeus, o gênero incluía quase todas as leguminosas mimosoídeas conhecidas. Das 47 relacionadas no "Codex Linneanus", apenas 6 são ainda consideradas como verdadeiras mimosas, tendo as restantes sido distribuídas em 16 gêneros distintos. Bentham e De Candolle, dentre outros eminentes botânicos do século XIX, foram os principais responsáveis por este retrabalhamento taxonômico.

O gênero Mimosa compreende atualmente mais de 400 espécies. É predominantemente americano, tendo escassos representantes na África e Ásia. No continente americano, é encontrado em todas as regiões quentes, desde o sul dos Estados Unidos até o Uruguai e centro da Argentina, faltando apenas no Chile, Patagônia e região andina (BURKART, 1952).

A taxonomia das Mimosas está fundamentada na célebre monografia "Revision of the Sub-order Mimoseae" (BENTHAM, 1875). São reconhecidas diversas séries botânicas, agrupadas em duas secções - Habbasia e Eumimosa distinguidas entre si pela presença de flores diplostêmones e isostêmones, respectivamente.

A ocorrência de flores isostêmones em Mimosa berroi Burk., determina sua inclusão na secção Eumimosa Benth. A cor amarela das flores, bem como os abundantes pêlos multicelulares ramificados, presentes em todos os órgãos externos da planta, justificam, por sua vez, a inclusão da espécie na série Lepidotae Benth.

Mimosa berroi é pouco conhecida no Rio Grande do Sul e espécie bastante rara, não tendo sido incluída na monografia de RAMBO (1966) sobre as leguminosas deste Estado brasileiro. A espécie foi originalmente descrita, com base em material coletado em Gruta de los Cuervos, no Departamento de Tacuarembó - Uruguai (BURKART, 1964). Sua única área de ocorrência conhecida até o momento no Rio Grande do Sul encontra-se em Aceguá, a poucos metros da Linha Divisória Internacional.

Mimosa berroi distingue-se por ser um sub-arbusto de ramos cilíndricos, com longos entrenós, e folhas unijugas, tendo 10-23 pares de folíolos 
imbricados, concolores e estrelado-pubescentes nas duas faces. Os capítulos são grandes, globosos e com cerca de $2 \mathrm{~cm}$ de diâmetro, quando abertas as flores. Estas são amarelas, tendo cálice campanulado glabro, corola tetradentada de tubo lepidoto, quatro filamentos estaminais livres até o receptáculo e ovário oboval, com estigma apical côncavo. Os frutos são multisseminados e híspido-setosos, providos de setas com base cônico-endurecida (BURKART, 1964).

A anatomia da madeira no gênero Mimosa é pouco conhecida, devido ao escasso interesse econômico de suas espécies.

COZZO (1951), em estudo de 11 espécies nativas da Argentina, observou uma ampla variação anatômica no material examinado, considerando-o "estruturalmente heterogêneo", pela inexistência de um traço comum ao grupo.

No conjunto de espécies examinadas por Cozzo, apenas Mimosa scabrella pertence à série Lepidotae Bentham. Para esta espécie, bem como para Mimosa adpressa (da série Obstrigosae Benth.), o autor anotou a estratificação do parênquima axial e elementos vasculares associados.

Para as espécies sul-brasileiras são conhecidos estudos descritivos apenas para Mimosa bimucronata (MARCHIORI, 1993), Mimosa cruenta (MARCHIORI, 1985), Mimosa daleoides (MARCHIORI, 1982), Mimosa eriocarpa (CARNIELETTO \& MARCHIORI, 1993), Mimosa scabrella (MARCHIORI, 1980; RICHTER \& CHARVET, 1973) e Mimosa sparsa (MACCARI \& MARCHIORI, 1994). A ontogenia do caule da bracatinga foi descrita por MARCHIORI (1988).

A estrutura do lenho de Mimosa berroi é desconhecida, inexistindo referências anatômicas sobre a mesma. O presente trabalho visa suprir esta lacuna e contribuir para o conhecimento taxonômico do gênero a que pertence.

\section{MATERIAL E MÉTODOS}

O material estudado foi coletado no Rio Grande do Sul e consiste de 5 amostras de madeira, incorporadas ao acervo do Herbário e Xiloteca do Departamento de Ciências Florestais (HDCF), da Universidade Federal de Santa Maria, com os números 3.227 a 3.231 . As coletas foram realizadas a 07/8/1987, nos arredores de Aceguá, Bagé - RS, pelo autor do presente trabalho. 
De cada amostra coletada foram preparados 3 corpos de prova do lenho, orientados para a obtenção de cortes anatômicos nos planos transversal, longitudinal radial e longitudinal tangencial, respectivamente. Os corpos de prova foram amolecidos por fervura em água e seccionados em micrótomo de deslizamento, regulado para cortes com espessura nominal de $18 \mu \mathrm{m}$.

Os cortes anatômicos foram coloridos com acridina-vermelha, crisoidina e azul-de-astra (DUJARDIN, 1964), desidratadas em série alcoólica, diafanizadas em xilol e montadas em lâminas permanentes. Usou-se Entellan como meio de montagem.

Para o preparo de lâminas de macerado, foram obtidos finos palitos de cada amostra, mediante fendilhamentos sucessivos de um corpo de prova, retirado da região mais externa do tecido lenhoso. Os palitos foram fervidos em água para a expulsão completa do ar e submetidos a dois banhos com solução de Jeffrey (FREUND, 1970), por periodos de 24 horas cada. A pasta de fibras resultante, foi colorida com safranina, desidratada em série alcoólica e conservada em recipiente hermético, com xilol. Para cada amostra de madeira foram preparadas diversas lâminas permanentes de macerado, tendo sido usado o mesmo meio de montagem anteriormente referido.

As medições anatômicas seguiram as normas COPANT (1973), com as modificações introduzidas por MARCHIORI (1980). Os dados quantitativos são apresentados na Tabela 1.

As fotomicrografias de detalhes anatômicos foram tomadas em aparelho Carl Zeiss, no Laboratório de Anatomia da Madeira, da Universidade Federal do Paraná.

\section{DESCRIÇÃO DA MADEIRA}

Vasos: Numerosíssimos (42 - 53 - $64 / \mathrm{mm}^{2}$ ), ocupando cerca de 11,3 \% da secção transversal da madeira. Porosidade difusa, uniforme (Figura 1.A). Poros em sua maioria solnários ou geminados (Figura 1.A-C), mas freqüentemente em múltiplos de até 7 , dispostos radialmente ou em cachos. Poros de secção oval quando solitários, pequenos $(27-41-58 \mu \mathrm{m})$ eventualmente preenchidos por conteúdo escuro (Figura 1.B-C). 
Elementos vasculares muito curtos (105 - $197-260 \mu \mathrm{m})$, com placas de perfuração simples geralmente transversais. Apêndices ausentes ou então curtos (7,5 - 24 - $75 \mu \mathrm{m})$, em apenas uma das extremidades.

Pontoações intervasculares alternas, arredondadas, pequenas (4 - 4,8 - $7 \mu \mathrm{m}$ ), ornamentadas e com abertura comumente inclusa, horizontal (Figura 3.B). Pontoações raio-vasculares pequenas (3 - 4,2 - $6 \mu \mathrm{m})$ e arredondadas, semelhantes às intervasculares. Pontoações parênquimo-vasculares em arranjo alterno, pequenas $(3,5-5,2-8,5 \mu \mathrm{m})$, arredondadas e semelhantes às anteriores (Figura 3.A,C).

Parênquima axial: Ocupando $17,3 \%$ do volume da madeira, em disposição paratraqueal vasicêntrica (Figura 1.B,C) e em estreitas faixas marginais. O parênquima axial mostra uma tendência à estratificação, quando se observa em secção longitudinal tangencial (Figura 3.A). Séries parenquimáticas com 157 - 189 - $260 \mu \mathrm{m}$ de altura, por 15 - 18 - $26 \mu \mathrm{m}$ de largura, e geralmente com 2 células. Células fusiformes, medindo 140 - 167 - $190 \mu \mathrm{m}$ de altura por 14 $16-19 \mu \mathrm{m}$ de largura.

Raios: Numerosos (6 - 8 - $10 / \mathrm{mm}$ ), ocupando $24,8 \%$ do volume da madeira (Figura 2.B,C) e em sua maioria com mais de 4 células de largura $(33,8$ $\%)$. Os raios com 1 a 3 células de largura ocorrem com freqüências que variam de 15 a $19 \%$. Tecido radial fracamente heterogêneo, composto por células quadradas, curtamente procumbentes e eretas (Figura 2.A).

Os raios multisseriados medem de 270 - 672 - 1.200 um de altura, com 13 - 33 - 60 células, por $32-57-73 \mu \mathrm{m}$ de largura. Associado aos raios, observam-se curtas células parenquimáticas axiais e séries cristalíferas, que simulam envolver os raios (Figura 2.C).

Células esclerosadas, latericuliformes, oleíferas, mucilaginosas, cristalíferas e perfuradas, ausentes do tecido radial.

Fibras: Tecido fibroso proeminente, ocupando $46,6 \%$ do volume da madeira. Fibras libriformes, não septadas, com pontoações simples em forma de diminutas fendas, mais abundantes na face radial da parede. Fibras muito curtas 

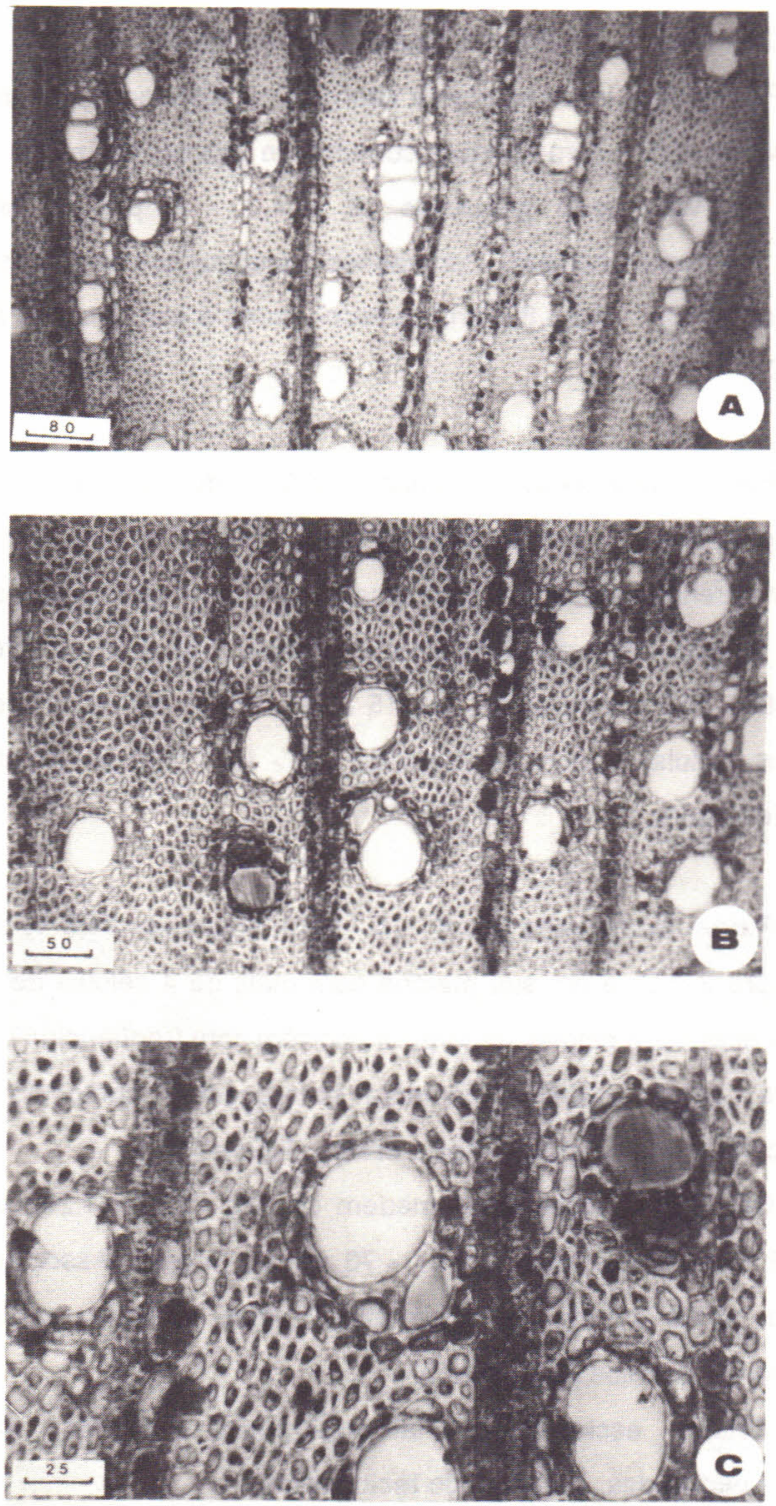

Figura 1. Aspectos da secção transversal da madeira (Todas as escalas em $\mu \mathrm{m}$ ). A. Porosidade difusa, com poros solitários, geminados ou em curtos múltiplos radiais e racemiformes. B. Poros de secção oval e pequeno diâmetro. C. Detalhe de poros e parênquima paratraqueal. 

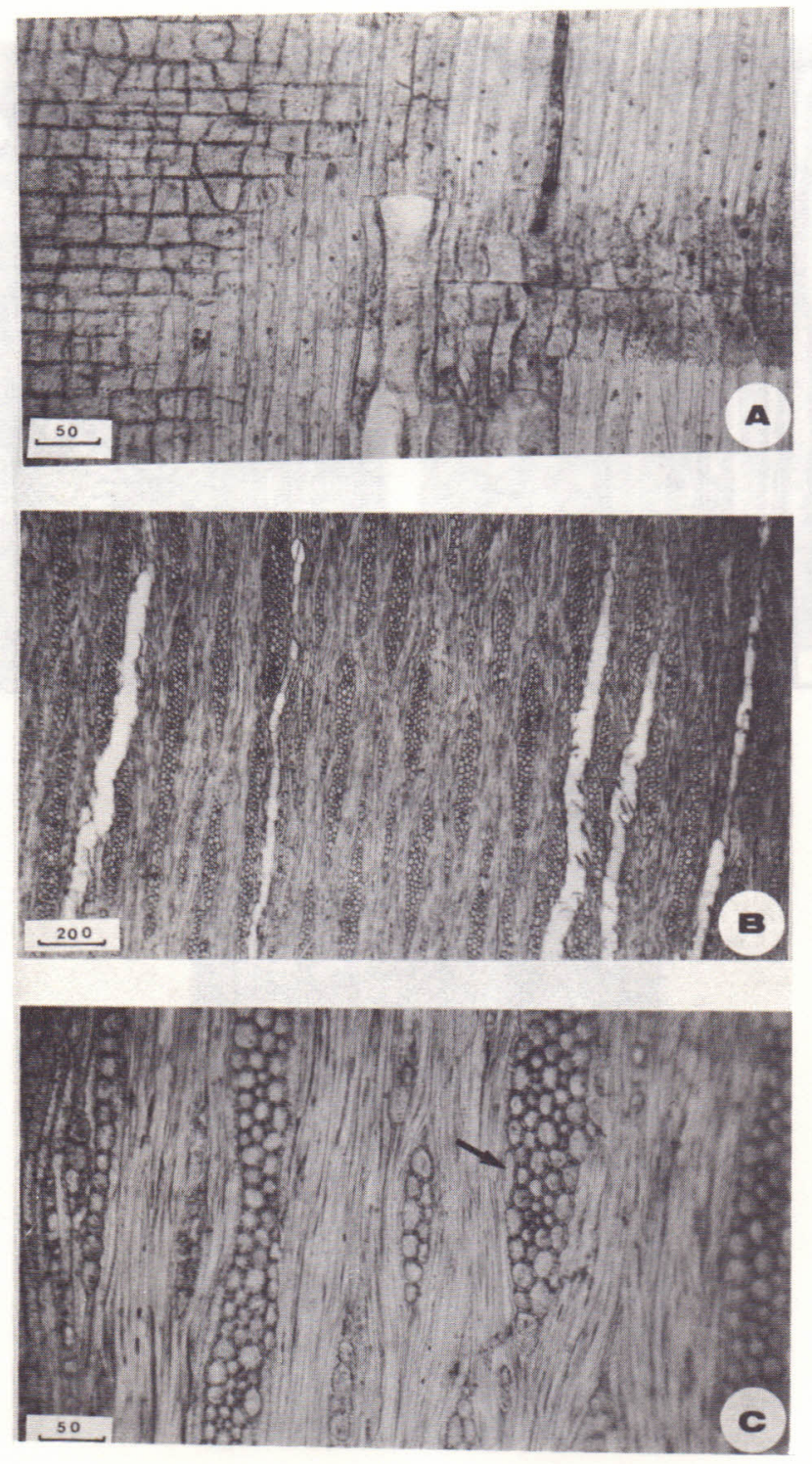

Figura 2. Aspectos anatômicos em cortes longitudinais (Todas as escalas em $\mu \mathrm{m}$ ). A. Tecido radial fracamente heterogêneo, com células quadradas, fracamente eretas e fracamente procumbemtes (secção radial). B. Raios normais e linhas vasculares (corte tangencial). C. Raio multisseriado e curtas células axiais (seia), que simulam envolver parcialmente $\bullet$ - raiô (corte tangencial). 

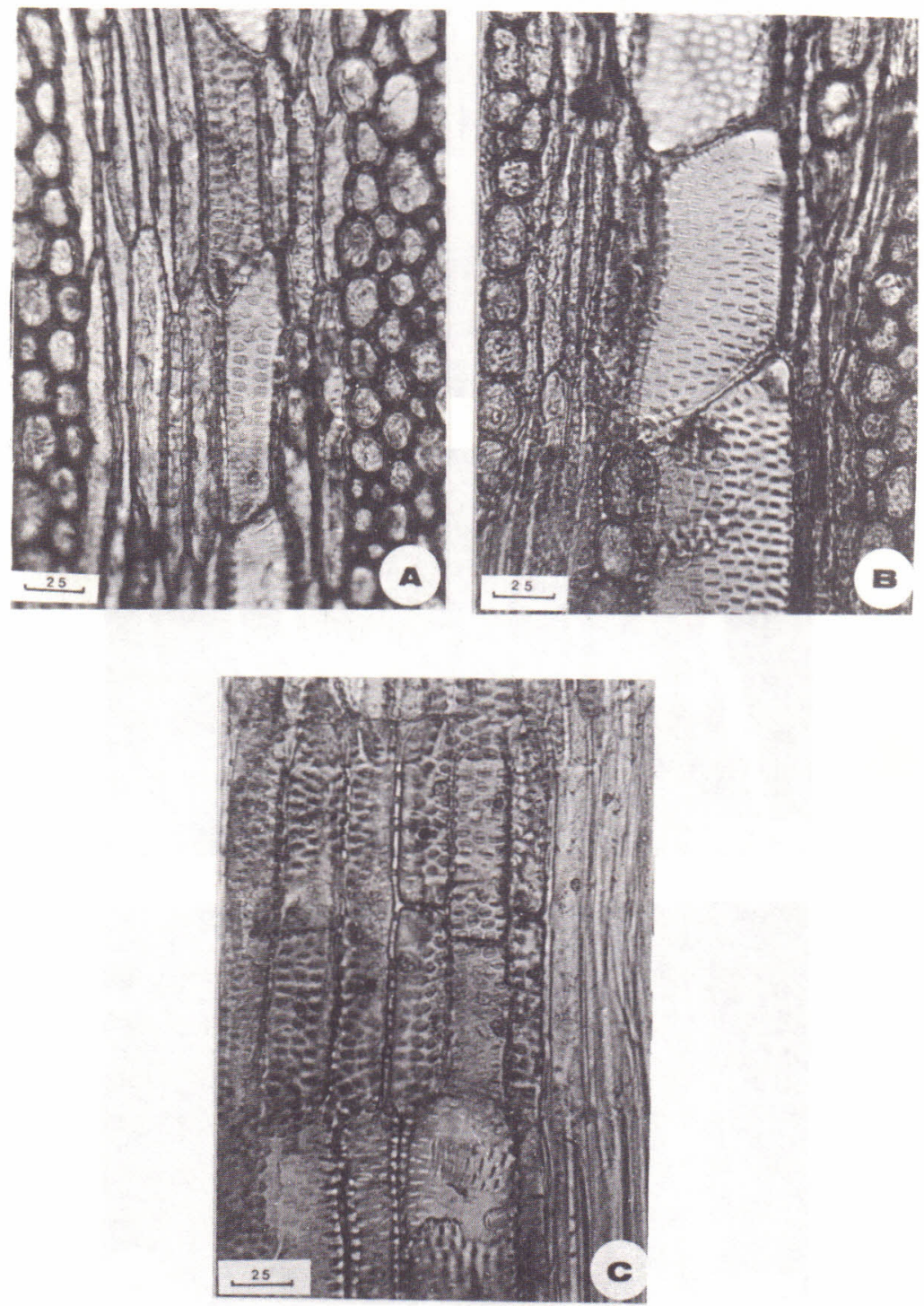

Figura 3. Aspectos anatômicos em cortes longitudinais (Todas as escalas em $\mu \mathrm{m}$ ). A. Secção tangencial, destacando o pontuado parênquimo-vascular e a tendência à estratificação do parênquima axial. B. Secção tangencial, destacando pontoações intervasculares ornamentadas, em arranjo alterno. C. Detalhe de pontoações parênquimo-vasculares, em corte radial. 
$(410$ - $567-760 \mu \mathrm{m})$, estreitas $(10,-13,9-18 \mu \mathrm{m})$ e de paredes delgadas a espessas $(2,5-3,8-5,0 \mu \mathrm{m})$.

Outros caracteres: Anéis de crescimento distintos, marcados por uma estreita camada de fibras radialmente achatadas, disposta no limite do lenho tardio. Canais celulares e intercelulares, cistos glandulares, tubos laticíferos e taniníferos, floema incluso, máculas medulares, células oleíferas e células mucilaginosas, ausentes. Estratificação observada apenas no parênquima axial. Cristais primáticos, presentes em séries parenquimáticas axiais dispersas no tecido fibroso.

\section{DISCUSSÃO}

Os principais caracteres anatômicos observados no xilema secundário de Mimosa berroi, tais como elementos vasculares muito curtos, placas de perfuração simples, pontoações alternas, parênquima paratraqueal e fibras libriformes, tem ocorrência generalizada na família Leguminosae (METCALFE \& CHALK, 1972, RECORD \& HESS, 1949; COZZO, 1950, 1951) e atestam um alto grau de especialização filogenética.

A presença de pontoações ornamentadas na madeira em estudo tem grande importância taxonômica, por ocorrer na quase totalidade das Leguminosas.

A tendência de estratificação do parênquima axial, observado em corte tangencial de Mimosa berroi, é caráter pouco freqüente em Mimosoideae, ao contrário das demais sub-famílias de Leguminosae. Sua presença nesta subfamília já havia sido descrita para Mimosa adpresssa e Mimosa scabrella, como sendo incompleta, porém uniforme (COZZO, 1951). Para esta última espécie, MARCHIORI (1980) também registrou a ocorrência de "estratificação parcial, de elementos vasculares e parênquima axial associado".

A heterogeneidade do tecido radial em Mimosa berroi, reunindo células quadradas, curtamente procumbentes e curtamente eretas, se contrar̃̃e à tendência referida por BARETTA-KUIPERS (1981), para o conjunto das Mimosoídeas. Cabe destacar que este aspecto foi também referido para Mimosa scabrella (COZZO, 1951. MARCHIORI. 1980), Mimosa daleoides (MARCHIORI, 
1982), Mimosa eriocarpa (CARNIELETTO et al., 1993) e Mimosa sparsa (MACCARI \& MARCHIORI, 1994).

A predominância de poros solitários na secção transversal da madeira de Mimosa berroi, havia sido registrada para outras espécies da série Lepidotae Benth, tais como: Mimosa scabrella (COZZO, 1951, MARCHIORI, 1980), Mimosa daleoides (MARCHIORI, 1982) e Mimosa eriocarpa (CARNIELETTO \& MARCHIORI, 1993), além de Mimosa sparsa (MACCARI \& MARCHIORI, 1994), pertencente à série Obstrigosae Benth. e Mimosa bimucronata (MARCHIORI, 1993), da série Rubicaules Benth. As espécies da série Stipellares Benth. distinguem-se facilmente quanto ao arranjo de poros, apresentando um nítido predomínio de múltiplos racemiformes e arranjo dendrítico, de acordo com o referido para Mimosa cruenta (MARCHIORI, 1985), Mimosa hassleriana e Mimosa uliginosa (COZZO, 1951).

Para a identificação de Mimosa berroi são ainda importantes a presença de fibras não septadas, de cristais romboédricos em séries parenquimáticas axiais dispersas no tecido fibroso e de curtas células parenquimáticas axiais, que simulam envolver parcialmente os raios.

\section{CONCLUSÕES}

A estrutura anatômica do xilema secundário de Mimosa berroi indica as seguintes conclusões:

- Os caracteres anatômicos atestam à espécie um alto grau de especialização filogenética;

- Os principais caracteres anatômicos observados coincidem com o descrito na literatura para a família Leguminosae;

- A nítida predominância de poros solitários ou em curtos múltiplos, corresponde ao descrito na literatura para outras espécies da série Lepidotae Benth., e contrasta com o referido na literatura para as espécies da série Stipellares Benth.;

- A tendência de estratificação do parênquima axial parece ter valor taxonômico para a identificação da série Lepidotae Benth.; 
- Tornam-se necessários estudos mais abrangentes, para a consolidação do conhecimento taxonômico das diferentes séries botânicas do gênero Mimosa.

\section{REFERÊNCIAS BIBLIOGRÁFICAS}

BARETTA-KUIPERS, T. Wood Anatomy of Leguminosae: its relevance to Taxonomy. In: POLHILL, R.M. , RAVEN, P.H. Advances in Legume Systematics. Kew, Ministery of Agriculture, Fisheries and Food, 1981. p. 677715.

BENTHAM, G. Revision of the suborder Mimoseae. Transact. Linnean Society of London, v. 30, p. 335-664, 1875.

BURKART, A. Las Leguminosas Argentinas Silvestres y Cultivadas. Buenos Aires: ACME, 1952. 569 p.

BURKART, A. Sinopsis de las especies de Mimosa de la serie Lepidotae. Darwiniana, v. 13, n. 2-4, p. 343-427, 1964.

CARNIELETTO, C., MARCHIORI, J.N.C. Anatomia da madeira de Mimosa eriocarpa Benth. Ciência Florestal, Santa Maria, v. 3, n. 1, p. 107-120, 1993.

COPANT - COMISSÃO PANAMERICANA DE NORMAS TECNICAS. Descrição macroscópica, microscópica e geral da madeira - esquema I de recomendação. Colômbia, 1973. 19 p. (COPANT 30).

COZZO, D. Anatomia del Leño Secundario de las Leguminosas Papilionoideas Argentinas. Revista del Instituto Nacional de Investigacion de las Ciencias Naturales, Buenos Aires, v.1, n. 7, p. 223-361, 1950.

COZZO, D. Anatomia del Leño Secundario de las Leguminosas Mimosoideas y Caesalpinioideas Argentinas Silvestres y Cultivadas. Revista del Instituto Nacional de Investigacion de las Ciencias Naturales, Buenos Aires, v. 2, n. 2, p. 63-146, 1951.

DUJARDIN, E.P. Eine neue Holz-zellulosenfaerbung. Mikroskosmos, n. 53, p. 94 , 1964.

FREUND H. Handbuch der Mikroskopie in der Technik. Frankfurt: Umsham Verlag, $1970.375 \mathrm{p}$. 
MACCARI, A., MARCHIORI, J.N.C. Estudo anatômico do xilema secundário de Mimosa sparsa Benth. Ciência Florestal, Santa Maria, v. 4, n. 1, p. 145-155, 1994.

MARCHIORI, J.N.C. Estudo anatômico do xilema secundário e da casca de algumas espécies dos gêneros Acacia e Mimosa, nativas no Estado do Rio Grande do Sul. Curitiba - PR. 186 p. Dissertação (Mestrado em Engenharia Florestal) - Curso de Pós-Graduação em Engenharia Florestal, Universidade Federal do Paraná, 1980.

MARCHIORI, J.N.C. A estrutura do xilema secundário de Mimosa daleoides Benth. (Leguminosae Mimosoideae). Ciência e Natura, Santa Maria, v. 4, p. 107-113, 1982.

MARCHIORI, J.N.C. Anatomia da madeira de Mimosa cruenta Benth. (Leguminosae Mimosoideae). Ciência e Natura, Santa Maria, v. 7, p. 73-81, 1985.

MARCHIORI, J.N.C. Ontogenia do caule de Mimosa scabrella Benth. In: CONGRESSO FLORESTAL ESTADUAL, VI, 1988, Nova Prata. Anais. Nova Prata, 1988. p. 1167-1177.

MARCHIORI, J.N.C. Anatomia da madeira e casca do maricá, Mimosa bimucronata (DC.) O. Ktze. Ciência Florestal, Santa Maria, v.3, n. 1, p. 85106, 1993.

METCALFE, C.R., CHALK, L. Anatomy of the Dicotyledons. Oxford: Clarendon Press, 1972. $1500 \mathrm{p}$.

RAMBO, B. Leguminosae Riograndenses. Pesquisas, Série Botânica, n. 23, p. 166, 1966.

RECORD, S.J., HESS, R.W. Timbers of the New World. New Haven: Yale University Press, 1949. 640 p.

RICHTER, H.G., CHARVET, L.M. Estudo e pesquisa sobre Mimosa scabrella. Floresta, Curitiba, v. 4, n. 2, p. 68-69, 1973. 
TABELA 1. Dados quantitativos da madeira de Mimosa berroi.

\begin{tabular}{|c|c|c|c|c|}
\hline CARACTERÍSTICA & $\begin{array}{l}\text { VALOR } \\
\text { MÍNIMO }\end{array}$ & MÉDIA & $\begin{array}{l}\text { VALOR } \\
\text { MÁXIMO }\end{array}$ & $\begin{array}{l}\text { DESVIO } \\
\text { PADRÃO }\end{array}$ \\
\hline 1. Fração de poros (\%) & 9,0 & 11,3 & 16,0 & 2,73 \\
\hline 2.Freqüência de poros (poros $/ \mathrm{mm}^{2}$ ) & 42,0 & 53,0 & 64,0 & 6,73 \\
\hline 3. Diâmetro poros solitários $(\mu \mathrm{m})$ & 27,0 & 41 & 58 & 6,48 \\
\hline 4. Comprimento elementos vasculares $(\mu \mathrm{m})$ & 105,0 & 197,0 & 260,0 & 37,80 \\
\hline 5. Comprimento de apêndices $(\mu \mathrm{m})$ & 7,5 & 24,0 & 75,0 & 19,00 \\
\hline 6. Diâmetro pontoações intervasculares $(\mu \mathrm{m})$ & 4,0 & 4,8 & 7,0 & 0,65 \\
\hline 7. Diâmetro pontoações raio-vasculares $(\mu \mathrm{m})$ & 3,0 & 4,2 & 6,0 & 0,71 \\
\hline 8. Diâmetro pont. parênquimo-vasculares $(\mu \mathrm{m})$ & 3,5 & 5,2 & 8,5 & 1,24 \\
\hline 9. Fração parênquima axial (\%) & 15,0 & 17,3 & 23,0 & 2,99 \\
\hline 10. Altura séries parênquima axial $(\mu \mathrm{m})$ & 157,0 & 189,0 & 260,0 & 34,42 \\
\hline 11. Largura séries parênquima axial $(\mu \mathrm{m})$ & 15,0 & 18,0 & 26,0 & 4,12 \\
\hline 12. Altura células fusiformes $(\mu \mathrm{m})$ & 140,0 & 167,0 & 190,0 & 16,33 \\
\hline 13. Largura células fusiformes $(\mu \mathrm{m})$ & 14,0 & 16,0 & 19,0 & 1,97 \\
\hline 14. Fração tecido radial (\%) & 19,0 & 24,8 & 28,0 & 3,12 \\
\hline 15. Freqüência de raios (raios $/ \mathrm{mm}$ ) & 6,0 & 8,0 & 10,0 & 1,09 \\
\hline 16. Fração raios 1 -seriados (\%) & 15,0 & 15,8 & 17,0 & 0,95 \\
\hline 17. Fração raios 2-seriados (\%) & 12,0 & 16,0 & 19,0 & 3,55 \\
\hline 18. Fração raios 3-seriados (\%) & 16,0 & 18,7 & 21,0 & 2,21 \\
\hline 19. Fração raios 4-seriados (\%) & 12,0 & 15,7 & 18,0 & 2,62 \\
\hline 20. Fração raios + 4-seriados (\%) & 33,0 & 33,8 & 36,0 & 1,50 \\
\hline 21. Altura raios multisseriados $(\mu \mathrm{m})$ & 270,0 & 672,0 & $1.200,0$ & 288,40 \\
\hline 22. Altura raios multisseriados (células) & 13 & 33 & 60 & 15,27 \\
\hline 23. Largura raios multisseriados $(\mu \mathrm{m})$ & 32,0 & 57,0 & 73,0 & 10,76 \\
\hline 24. Largura raios multisseriados (células) & 2 & 4,7 & 7 & 1,31 \\
\hline 25. Fração de fibras (\%) & 42,0 & 46,6 & 49,0 & 2,73 \\
\hline 26. Comprimento de fibras $(\mu \mathrm{m})$ & 410,0 & 567,0 & 760,0 & 74,48 \\
\hline 27. Diâmetro de fibras $(\mu \mathrm{m})$ & 10,0 & 13,9 & 18,0 & 1,98 \\
\hline 28. Diâmetro lume de fibras $(\mu \mathrm{m})$ & 2,5 & 6,3 & 10,0 & 1,89 \\
\hline 29. Espessura parede de fibras $(\mu \mathrm{m})$ & 2,5 & 3,8 & 5,0 & 0,74 \\
\hline
\end{tabular}


